\title{
Tratamento de lixiviado por infiltração rápida como alternativa para cidades de pequeno porte
}

\section{Leachate treatment by rapid infiltration process as an alternative for small towns}

\author{
Maria Claudia Lima Couto \\ Engenheira Civil e Mestre em Engenharia Ambiental pela Universidade Federal do Espírito Santo (UFES) - Vitória (ES), Brasil. Doutoranda em Engenharia \\ Sanitária e Ambiental pela Universidade Federal de Minas Gerais (UFMG) - Belo Horizonte (MG), Brasil. \\ Florindo dos Santos Braga \\ Engenheiro Civil. Doutor em Hidráulica e Saneamento pela Escola de Engenharia de São Carlos (EESC) - São Carlos (SP), Brasil. Professor Associado do \\ Departamento de Engenharia Ambiental da UFES - Vitória (ES), Brasil.
}

\author{
Liséte Celina Lange \\ Química. Doutora em Tecnologia Ambiental pela University of London. Professora Associada do Departamento de Engenharia Sanitária e \\ Ambiental da UFMG - Belo Horizonte (MG), Brasil.
}

\begin{abstract}
Resumo
O objetivo deste artigo é apresentar um estudo experimental de viabilidade técnica do processo de Infiltração Rápida (IR) no tratamento de lixiviado de um aterro sanitário para a remoção de matéria orgânica e nutrientes. O estudo foi realizado em escala piloto com leitos filtrantes de areia e tijolo cerâmico triturado. O monitoramento do desempenho dos reatores foi feito por meio dos parâmetros Demanda Química de Oxigênio (DQO), Sólidos Suspensos Totais (SST), Fósforo Total $\left(\mathrm{P}_{\text {Total }}\right)$, nitrogênio total Kjeldahl (NTK), N-NH${ }_{3}, \mathrm{~N}_{-} \mathrm{NO}_{3}, \mathrm{~N}-\mathrm{NO}_{2}$; alcalinidade, $\mathrm{pH}$ e temperatura. A redução média nos reatores com leito de areia média foi 32\% de DQO e 43\% de NTK, com leito de areia fina 27\% de DQO e 47\% de NTK e no reator com leito de tijolo cerâmico triturado 70\% de DQO e $54 \%$ de NTK. Os resultados obtidos neste estudo são parâmetros para elaboração de projetos com processo IR em escala real para tratamento de lixiviado de aterros sanitários, especialmente para cidades de pequeno porte.
\end{abstract}

Palavras-chave: lixiviado; aterro sanitário; tratamento biológico; infiltração rápida.

\section{Abstract}

The aim of this article is to present an experimental study applying the Rapid Infiltration (RI) technique during the treatment of a landfill leachate in order to remove organic matter and nutrients. The study was conducted in a pilot scale with filter media were of sand and triturated ceramic brick. The monitoring of the reactors performance was made through parameters Chemical Oxygen Demand (COD), Total Suspended Solids (TSS), Phosphorus Total ( $P_{\text {Total }}$ ), Total

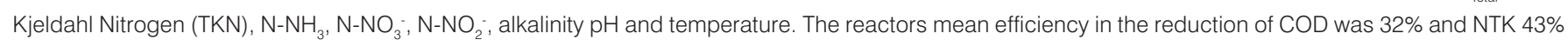
for the reactor with sand media, for the reactor with thin sand media the COD was of $27 \%$ and TKN of $47 \%$ and for the reactor with triturated ceramic brick COD was of $70 \%$ and TKN of $54 \%$. The results obtained in this study are very important to subsidy the elaboration of design of the RI process in field scale for landfill leachate treatment, mainly for small towns.

Keywords: leachate; landfill; biologic treatment; rapid infiltration beds.

\section{Introdução}

A disposição final dos rejeitos dos resíduos sólidos urbanos (RSU) em aterros sanitários é a última das etapas do seu gerenciamento, sendo a técnica considerada de menor custo e ambientalmente mais recomendada para localidades onde há disponibilidade de área e escassez de recursos financeiros. A geração do lixiviado depende da vários fatores, ocorrendo na maioria das situações. Além disso, é grande a variabilidade das características dos contaminantes do lixiviado de um aterro para o outro.

O tratamento do lixiviado por meio de processos biológicos é uma alternativa viável comprovada em muitos estudos descritos por Gomes (2009). O tratamento biológico do lixiviado é geralmente feito por meio de lagoas de estabilização que requerem grandes áreas e longo tempo de detenção. Outros sistemas como filtros biológicos aeróbios e anaeróbios também são alternativas possíveis. Em alguns 
casos, nesses sistemas, o lixiviado é misturado ao esgoto sanitário para ser tratado. A escolha do processo mais adequado para tratar lixiviado de um aterro requer um estudo minucioso de viabilidade técnica e econômica.

Os filtros biológicos têm sido empregados com sucesso no tratamento de lixiviados, principalmente no que se refere à remoção de nitrogênio amoniacal, de acordo com Jokela et al. (2002), Lekang e Kleppe (2000), Eldyasti et al. (2011), Sanford et al. (1995), Welander, Henrysson e Welander (1998). Segundo Renou et al. (2008), esses tratamentos têm demonstrado eficácia na remoção de material orgânico e nitrogênio de lixiviados novos, com razão Demanda Bioquímica de Oxigênio (DBO)/Demanda Química de Oxigênio (DQO)>0,5.

Entre as vantagens para o tratamento de lixiviado com filtros biológicos se incluem: pouca exigência de manutenção, instalação barata e elevada tolerância às variações de carga orgânica e hidráulica. Outro aspecto importante é o fato de o leito filtrante ter uma grande área superficial onde o biofilme pode crescer (COUTO, 2004).

A infiltração rápida (IR) é um processo de tratamento de efluentes no solo que promove a remoção dos poluentes por meio de filtração das substâncias presentes quando a água residuária percola por meio dele (BRAGA, 1998).

Bidone, Povinelli e Cotrim (1997) avaliaram a eficiência do processo de infiltração rápida em escala piloto no tratamento de lixiviado de um aterro antigo, utilizando leitos de cacos de tijolos cerâmicos, obtendo uma remoção de 16\% de DQO e uma redução de 87\% de NTK.

Jokela et al. (2002), em estudos em escala piloto com reatores aeróbios com fluxo ascendente, aerados por difusores submersos e tendo como material filtrante tijolo triturado, obtiveram eficiência na nitrificação acima de $90 \%$ para taxas de aplicação de 100-130 mgN-NH . $^{-1}$. dia. Segundo os autores, os meios filtrantes constituídos de tijolo triturado promovem uma rápida e estável nitrificação do lixiviado, com a vantagem do baixo custo do material.

Estudos realizados por Yidong et al. (2012) buscaram resolver o problema da falta de tratamento adequado para lixiviados gerados em aterros controlados ou provenientes da remediação de lixões. Os reatores eram em escala real e constituídos por blocos, tendo em sua composição 50\% de solo e os outros 50\% eram resíduos: 30\% de pó de serragem de madeira, 10\% de carvão vegetal e 10\% de limalhas de ferro, materiais de baixo custo e facilmente disponíveis nas áreas rurais.

O sistema (IR) é de simples operação e utiliza materiais de baixo custo, principalmente areia ou material cerâmico triturado que pode ser reaproveitado dos rejeitos da construção civil. Esses aspectos demonstram a viabilidade dessa técnica em reatores em escala real, por meio de tanques em alvenaria de tijolos ou concreto e preenchidos com material filtrante, para o tratamento de lixiviados de aterros de municípios de pequeno porte, geralmente com escassez de recursos financeiros e pouca mão de obra técnica especializada para implantar e operar sistemas de tratamento sofisticados.

O trabalho foi realizado em escala piloto e sua metodologia de monitoramento e resultados obtidos servem de base para a construção de reatores IR experimentais em escala mais próxima da real que possibilitem a coleta do efluente tratado para monitoramento e análise e lançamento final adequado em corpos receptores ou, se necessário, envio a um sistema de tratamento complementar.

\section{Materiais e métodos}

\section{Características do local do estudo}

O estudo foi desenvolvido no município de Vitória, no estado do Espírito Santo, Brasil. O lixiviado estudado foi coletado no aterro sanitário localizado em um município da Região Metropolitana da Grande Vitória. Nesse aterro, são dispostos os RSU de Vitória e de vários municípios do estado. A célula do aterro sanitário de onde o lixiviado foi coletado entrou em operação em outubro de 2002. As amostras de lixiviado eram coletadas semanalmente durante o período do estudo. Os dados de temperatura e precipitação foram obtidos da estação de monitoramento do ar da Grande Vitória localizada em Carapina - Serra (ES).

\section{Construção dos reatores}

Foram construídos 5 reatores em escala piloto, com tubos de PVC de $150 \mathrm{~mm}$ de diâmetro, com saída de lixiviado tratado em uma torneira acoplada a um cap de $100 \mathrm{~mm}$ na base do reator, para controle da vazão de saída e coleta de amostras (Figura 1). Esses

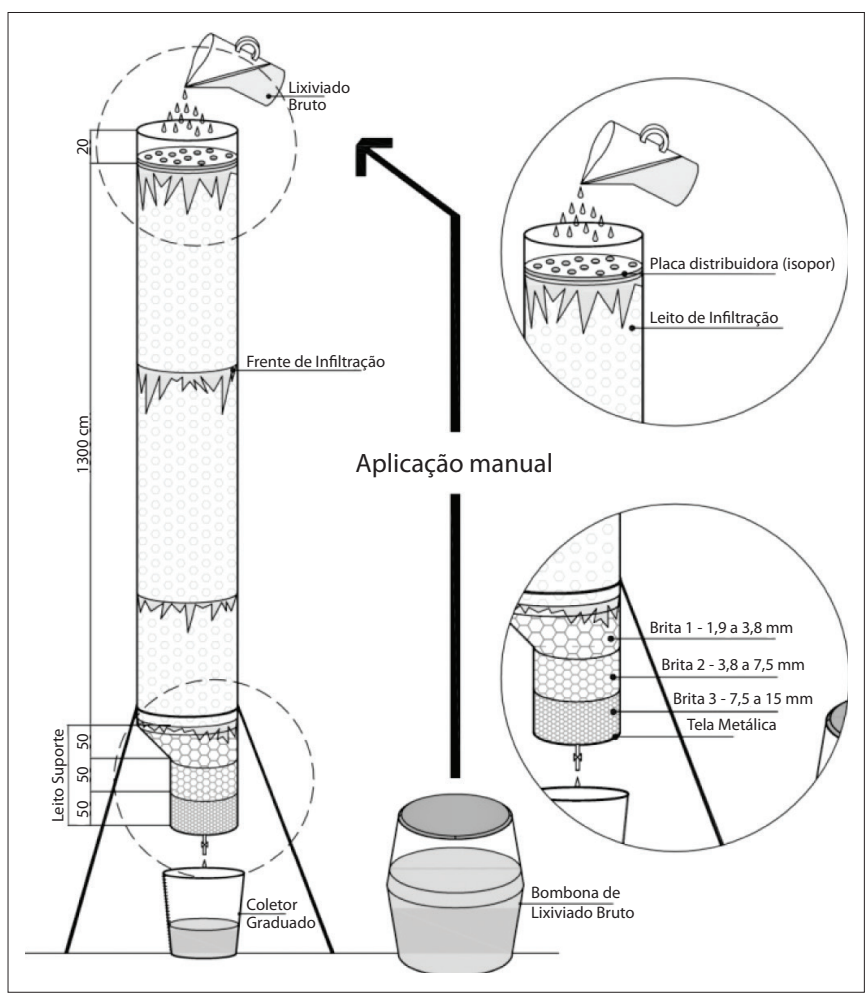

Figura 1 - Detalhes construtivos e operacionais dos reatores. 
reatores foram preenchidos manualmente com camadas de $5 \mathrm{~cm}$ de brita de granulometrias 1, 2 e 3, sucessivamente, formando uma camada suporte de $15 \mathrm{~cm}$. Em seguida, foram preenchidos com material filtrante, formando um leito de 1,30 m de altura em cada reator. Os reatores foram construídos em local sem cobertura, sujeitos, portanto, às intempéries

\section{Etapas da pesquisa}

O estudo foi realizado em quatro etapas, sendo que a Etapa 2 foi dividida em duas fases.

Etapa 1 - Foi realizada a caracterização do lixiviado bruto, por meio dos parâmetros DBO, DQO, Sólidos Suspensos Totais (SST), Fósforo Total $\left(\mathrm{P}_{\text {Total }}\right)$ e pH, e testes preliminares com dois reatores com leitos de areia média (IRAM-1 e IRAM-2). Os reatores foram operados em taxas distintas de 10,3 cm.dia ${ }^{-1}$ e $6,4 \mathrm{~cm} \cdot \mathrm{dia}^{-1}$, respectivamente, por 52 dias.

Etapa 2 - Nesta etapa, foram realizados testes com reatores com leitos de areia média (IRAM) e areia fina (IRAF). Ambos foram operados à taxa de $6,4 \mathrm{~cm} \cdot$ dia $^{-1}$. Na Fase 1, com duração de 113 dias, avaliou-se o desempenho dos reatores até a colmatação dos leitos. Na Fase 2, com duração de 52 dias, avaliou-se a continuidade da eficiência no tratamento após os reatores serem recuperados (IRAMR e IRAFR) com raspagem manual da camada colmatada e recomposição com material virgem.

Etapa 3 - Nesta etapa, com duração de 63 dias, foram realizados testes com reator preenchido com tijolo cerâmico triturado (IRTC), operado à taxa de $6,4 \mathrm{~cm} \cdot$ dia $^{-1}$ até a colmatação do leito.

Etapa 4 - Avaliou-se a contaminação das camadas colmatadas dos reatores IRAF, IRAM e IRTC, visando ao seu descarte adequado. Foram realizadas análise de $\mathrm{Cd}$ e $\mathrm{Pb}$ dos extratos lixiviados e $\mathrm{Cd}$, $\mathrm{Pb}, \mathrm{Cu}, \mathrm{Fe}, \mathrm{Mn}$ e $\mathrm{Zn}$ dos extratos solubilizados, obtidos conforme a ABNT (2004b, 2004c).

\section{Características operacionais do sistema}

O ciclo operacional adotado durante o estudo foi de sete dias, sendo quatro dias de aplicação e três dias de repouso. Nos dias de aplicação, a alimentação dos reatores era dividida em 4 frações iguais, com intervalos de 1,5 h, em um total de 6,0 h.

A alimentação dos reatores era manual, e a coleta de amostras para análise era realizada duas vezes por semana. Além disso, testes de infiltração com água foram feitos nos dois primeiros dias de operação e medições de volume do efluente tratado foram feitos diariamente para acompanhar a evolução do processo de colmatação dos leitos.

\section{Monitoramento e análise dos dados}

O monitoramento do estudo foi constituído por coleta de amostras do lixiviado bruto e tratado, análises laboratoriais, controle de volume do lixiviado tratado e elaboração de curvas de vazões para acompanhamento do processo de colmatação dos leitos. As análises de laboratório foram realizadas conforme as normas da ABNT (1988, 2004a, 2004b, 2004c) e APHA, AWWA, WEF (2005). Foi utilizado o pacote estatístico MINITAB versão 13 e aplicado o teste ANOVA (Analyse of Variance) para análise estatística dos dados.

As concentrações de $\mathrm{Cd}$ e $\mathrm{Pb}$ (mg. $\mathrm{L}^{-1}$ ) foram obtidas por espectrometria de absorção atômica com forno de grafite (GF-AAS), enquanto as concentrações dos demais metais (mg. $\left.\mathrm{L}^{-1}\right)$ foram obtidas por espectrometria de absorção atômica com chama (F-AAS)

\section{Resultados e discussão}

\section{Caracterização dos leitos filtrantes}

A IR requer materiais granulares com boa porosidade aparente e grande área superficial para possibilitar desenvolvimento e presença de biomassa em um meio insaturado. Para atender essa condição, os leitos filtrantes dos reatores foram constituídos de areia média, areia fina e material cerâmico triturado com granulometria semelhante à areia média. A caracterização desses materiais foi realizada conforme ABNT (1988). A Tabela 1 apresenta as características físicas de granulometria e permeabilidade dos leitos.

\section{Etapa 1}

Nesta etapa, foram analisadas cinco amostras de lixiviado bruto. As concentrações médias dessas amostras foram: $1.746 \mathrm{mgO}_{2} \cdot \mathrm{L}^{-1} \mathrm{de}$ $\mathrm{DBO}, 3.816 \mathrm{mgO}_{2} \cdot \mathrm{L}^{-1}$ de $\mathrm{DQO}$ e pH de 8,6. A relação DBO/DQO, que é um indicador do nível de degradação biológica do lixiviado, foi de 0,46. Segundo Gomes (2009), aterros novos têm relação DBO/DQO que variam de 0,50 a 0,80, enquanto que em aterros antigos essa relação varia de 0,04 a 0,08.

\section{Desempenho de IRAM-1 e IRAM-2}

Na Etapa 1, o lixiviado foi aplicado durante 52 dias a uma taxa de $10,3 \mathrm{~cm} \cdot \mathrm{dia}^{-1}$ no IRAM-1 e de 6,4 cm.dia ${ }^{-1}$ no IRAM-2, conforme ciclo de aplicação proposto. Na Tabela 2, são apresentados os resultados dos parâmetros monitorados.

Tabela 1 - Características dos leitos filtrantes.

\begin{tabular}{lcccc} 
Parâmetros & Areia fina & $\begin{array}{c}\text { Areia } \\
\text { média }\end{array}$ & $\begin{array}{c}\text { Tijolo } \\
\text { triturado }\end{array}$ & Unidade \\
\hline Areia grossa $\left(\mathrm{P}_{4}-\mathrm{P}_{10}\right)$ & 0,34 & 0,00 & 18,50 & $(\%)$ \\
\hline Areia média $\left(\mathrm{P}_{10}-\mathrm{P}_{50}\right)$ & 25,07 & 66,37 & 42,66 & $(\%)$ \\
\hline Areia fina $\left(\mathrm{P}_{30}-\mathrm{P}_{100}\right)$ & 74,56 & 33,63 & 30,54 & $(\%)$ \\
\hline $\begin{array}{l}\text { Diâmetro efetivo }\left(\mathrm{d}_{10}\right) \\
\text { Coef. de uniformida- }\end{array}$ & 0,17 & 0,34 & 0,095 & $\mathrm{~mm}$ \\
de $\left(\mathrm{Cu}=\mathrm{d}_{10} / \mathrm{d}_{60}\right)$ & 1,82 & 1,5 & 17,89 & - \\
$\begin{array}{l}\text { Permeabilidade } \\
(20 \text { 으 })\end{array}$ & 47,16 & 62,4 & 55,37 & $\mathrm{~cm} / \mathrm{h}$
\end{tabular}

Coef.: Coeficiente 
A eficiência na remoção da DQO foi maior no IRAM-2. Quando da aplicação do teste estatístico ANOVA aos resultados da Etapa 1 dos reatores IRAM-1 e IRAM-2, verificou-se que para o parâmetro DQO ( $p=0,02)$ e SST $(p=0,035)$ há evidência significativa de que os tratamentos foram distintos.

\section{Etapa 2}

\section{Fase 1 - Desempenho dos reatores IRAF e IRAM}

Na Fase 1 da Etapa 2, aplicou-se lixiviado nos IRAF e IRAM a uma taxa de 6,4 cm.dia ${ }^{-1}$, durante 113 dias. Na Tabela 3, são apresentados os resultados dos parâmetros monitorados.

Da comparação entre os desempenhos dos reatores IRAF e IRAM verificou-se que para alguns parâmetros como DQO, SST e Ptotal o leito de areia média apresentou melhor desempenho. A variação da DQO ao longo do tempo, tanto do lixiviado bruto como do lixiviado tratado dos reatores é mostrada na Figura 2. Nesse período, a temperatura média foi de $21,9^{\circ} \mathrm{C}$, e a taxa média de precipitação foi de $2,19 \mathrm{~mm}$.

Observa-se que, quanto a DQO, os reatores IRAF e IRAM apresentam comportamentos semelhantes e que sofreram influência com as mudanças de concentração do lixiviado bruto. A variação de temperatura também influenciou. Nos dias com quedas bruscas na temperatura, ocorreram também quedas nas eficiências, principalmente no reator IRAM. O comportamento dos reatores na Etapa 2 - Fase 1 em relação a de $\mathrm{N}_{-} \mathrm{NH}_{3}$ é apresentado na Figura 3.
Para os dois reatores IRAF e IRAM, o período de redução de nitrato no efluente coincide com o período em que ocorre um aumento das concentrações de DQO no lixiviado bruto, diminuindo assim a eficiência na redução da amônia, pois o oxigênio passou a ser requisitado para a oxidação da matéria orgânica, reduzindo a nitrificação.

\section{Colmatação dos leitos}

Os reatores IRAF e IRAM foram operados por 113 dias. Após esse momento, não foi mais possível a operação devido à colmatação dos leitos, constatada pela formação de uma lâmina de lixiviado estagnada na superfície de cada reator. Nesses reatores, foram feitas 2 raspagens com $3 \mathrm{~cm}$ de profundidade cada. Após cada raspagem, foram feitos testes de vazão para verificar o comportamento hidráulico deles. Na Figura 4, apresentam-se os resultados dos testes de vazão.

Após a retirada dos primeiros $3 \mathrm{~cm}$ superficiais, o reator IRAM mostrou uma melhor recuperação da vazão em relação ao IRAF. Isso ocorreu não só na superfície, mas também em profundidade, já que mesmo após a retirada de $6 \mathrm{~cm}$ o comportamento hidráulico do IRAF não se recuperou.

\section{Fase 2 - Recuperação da eficiência após substituição das camadas colmatadas}

Os resultados obtidos na Etapa 2 - Fase 2 são referentes à operação dos leitos recuperados do IRAFR e IRAMR após a raspagem das camadas colmatadas e reposição com material virgem. Esta etapa teve uma duração de 52 dias. O desempenho dos reatores IRAFR e IRAMR

Tabela 2 - Resultados do desempenho dos reatores com leito de Areia Média (1 e 2) na Etapa 1.

\begin{tabular}{|c|c|c|c|c|c|c|c|c|c|c|c|}
\hline \multirow{2}{*}{ Parâmetros } & \multicolumn{3}{|c|}{ Lixiviado bruto } & \multicolumn{4}{|c|}{ Lixiviado tratado IRAM-1 } & \multicolumn{4}{|c|}{ Lixiviado tratado IRAM-2 } \\
\hline & $n$ & média & DP & $\mathrm{n}$ & média & DP & $E(\%)$ & $\mathrm{n}$ & média & DP & $E(\%)$ \\
\hline $\mathrm{DQO}\left(\mathrm{mgO}_{2} \cdot \mathrm{L}^{-1}\right)$ & 14 & 3.629 & 574 & 15 & 2.938 & 536,1 & 18,9 & 15 & 2.600 & 446 & 27,8 \\
\hline $\mathrm{DBO}\left(\mathrm{mgO}_{2} \cdot \mathrm{L}^{-1}\right)$ & 5 & 1.746 & 149 & 5 & 1.244 & 72,4 & 29 & 5 & 1.186 & 79 & 32,1 \\
\hline $\mathrm{SST}\left(\mathrm{mg} \cdot \mathrm{L}^{-1}\right)$ & 10 & 368 & 86 & 10 & 141 & 9,8 & 62 & 10 & 100 & 23,5 & 72,8 \\
\hline$P_{\text {total }}\left(m g . L^{-1}\right)$ & 8 & 18,5 & 2,1 & 8 & 9,4 & 1,0 & 49 & 8 & 7,2 & 1,0 & 61,1 \\
\hline $\mathrm{pH}$ & 7 & 8,6 & 0,2 & 7 & 8,4 & 0,1 & $\mathrm{Na}$ & 7 & 8,3 & 0,1 & $\mathrm{Na}$ \\
\hline
\end{tabular}

E: eficiência de tratamento; Na: não se aplica; DQO: demanda química de oxigênio; DBO: demanda bioquímica de oxigênio; SST: sólidos suspensos totais; $\mathrm{P}_{\text {total }}$ Fósforo Total; IRAM: reatores com leito de areia média; DP: desvio-padrão.

Tabela 3 - Resultados do desempenho dos reatores com leito de Areia Fina e Areia Média - Etapa 2 - Fase 1.

\begin{tabular}{|c|c|c|c|c|c|c|c|c|c|c|c|}
\hline \multirow{2}{*}{ Parâmetros } & \multicolumn{3}{|c|}{ Lixiviado bruto } & \multicolumn{4}{|c|}{ Lixiviado tratado IRAF } & \multicolumn{4}{|c|}{ Lixiviado tratado IRAM } \\
\hline & $\mathrm{n}$ & média & DP & $\mathrm{n}$ & média & DP & $E(\%)$ & $\mathrm{n}$ & média & DP & $E(\%)$ \\
\hline $\mathrm{DQO}\left(\mathrm{mgO}_{2} \cdot \mathrm{L}^{-1}\right)$ & 32 & 6.214 & 2.901 & 32 & 4.336 & 1.768 & 27,9 & 32 & 4.011 & 1.497 & 32,3 \\
\hline SST (mg. $\left.\mathrm{L}^{-1}\right)$ & 32 & 268 & 101 & 32 & 113 & 54 & 58 & 32 & 99 & 29 & 63 \\
\hline N-NTK (mgN.L-1) & 17 & 2.248 & 608 & 17 & 1.192 & 495 & 47 & 17 & 1.284 & 555 & 43 \\
\hline $\mathrm{N}-\mathrm{NH}_{3}\left(\mathrm{mgN} \cdot \mathrm{L}^{-1}\right)$ & 17 & 1.639 & 467 & 17 & 931 & 374 & 43 & 17 & 1.014 & 492 & 38 \\
\hline $\mathrm{N}-\mathrm{NO}_{3}{ }^{-}\left(\mathrm{mgN} \cdot \mathrm{L}^{-1}\right)$ & 17 & $<0,001$ & $\mathrm{Na}$ & 17 & 135 & 156 & $\mathrm{Na}$ & 17 & 169 & 187 & $\mathrm{Na}$ \\
\hline $\mathrm{N}-\mathrm{NO}_{2}-\left(\mathrm{mgN} \cdot \mathrm{L}^{-1}\right)$ & 17 & $<0,001$ & $\mathrm{Na}$ & 17 & 25 & 40 & $\mathrm{Na}$ & 17 & 36 & 53 & $\mathrm{Na}$ \\
\hline$P_{\text {total }}\left(m g \cdot L^{-1}\right)$ & 19 & 16,6 & 1,7 & 17 & 11 & 2,5 & 34 & 17 & 9,7 & 2,4 & 41,6 \\
\hline $\mathrm{pH}$ & 17 & 8,3 & 0,2 & 17 & 8,7 & 0,1 & - & 17 & 8,7 & 0,1 & $\mathrm{Na}$ \\
\hline $\begin{array}{l}\text { Alc. } \\
\left(\mathrm{mgCaCO}_{3} . \mathrm{L}-1\right)\end{array}$ & 17 & 10.824 & 648 & 17 & 9.379 & 633 & 13,3 & 17 & 9.265 & 596 & 14,4 \\
\hline
\end{tabular}

E: eficiência de tratamento; Na: não se aplica; DQO: demanda química de oxigênio; SST: sólidos suspensos totais; $\mathrm{P}_{\text {total }}$ : Fósforo Total; IRAF: reator com leito de areia fina; IRAM: reator com leito de areia média; Alc.: alcalinidade; DP: desvio-padrão. 
é mostrado na Tabela 4. Nesse período, a temperatura média foi de $24,7^{\circ} \mathrm{C}$, e a taxa média de precipitação foi de $7,31 \mathrm{~mm}$.

O comportamento dos reatores IRAFR e IRAMR ao longo desta Etapa 2 - Fase 2 em relação à redução da DQO é apresentado na Figura 5.

O aumento da eficiência dos reatores logo no início desta Etapa 2 Fase 2, em relação ao final da Etapa 2 - Fase 1, pode ter ocorrido devido ao período chuvoso que provocou a diluição dos contaminantes, já que os reatores eram desprovidos de cobertura. No entanto, a chuva também pode ter provocado a lavagem dos leitos, reduzindo assim o número de microrganismos responsáveis pela degradação dos poluentes orgânicos. Isso fez com que, logo após o período chuvoso, a eficiência dos reatores reduzisse. Com a recuperação dessa biota, observou-se novamente um aumento de eficiência. A concentração de DQO no lixiviado bruto sofreu uma grande redução no período chuvoso, o que pode ter influenciado o processo de tratamento.

O comportamento dos reatores IRAFR e IRAMR ao longo desta Etapa 2 - Fase 2 em relação à redução de $\mathrm{N}_{-} \mathrm{NH}_{3}$ é apresentado na Figura 6.

No IRAMR, ocorreu também nitrificação logo no início da operação, se mantendo por todo o período operacional desta etapa. Para os dois reatores, IRAFR e IRAMR, o período de redução de nitrato no efluente coincide com o período em que ocorre um aumento das concentrações de DQO no lixiviado bruto afluente, diminuindo assim a eficiência na redução da amônia, pois o oxigênio passou a ser requisitado para a oxidação da matéria orgânica, inibindo a nitrificação. Portanto, a redução das concentrações de nitrato está relacionada tanto com a redução de sua produção como com uma provável

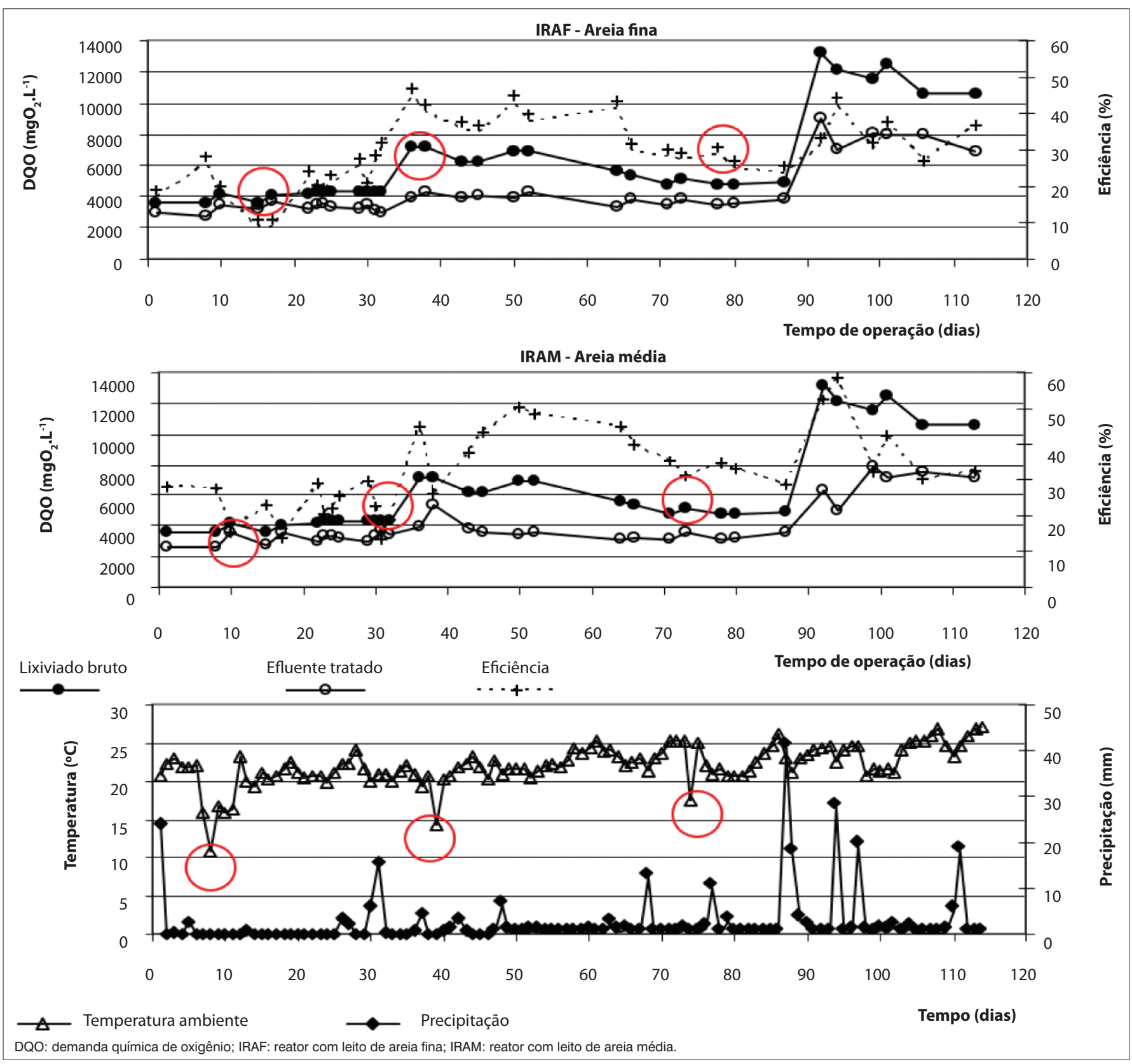

Figura 2 - Variação temporal das concentrações de demanda química de oxigênio na Etapa 2 - Fase 1 e variação de temperatura e precipitação. 


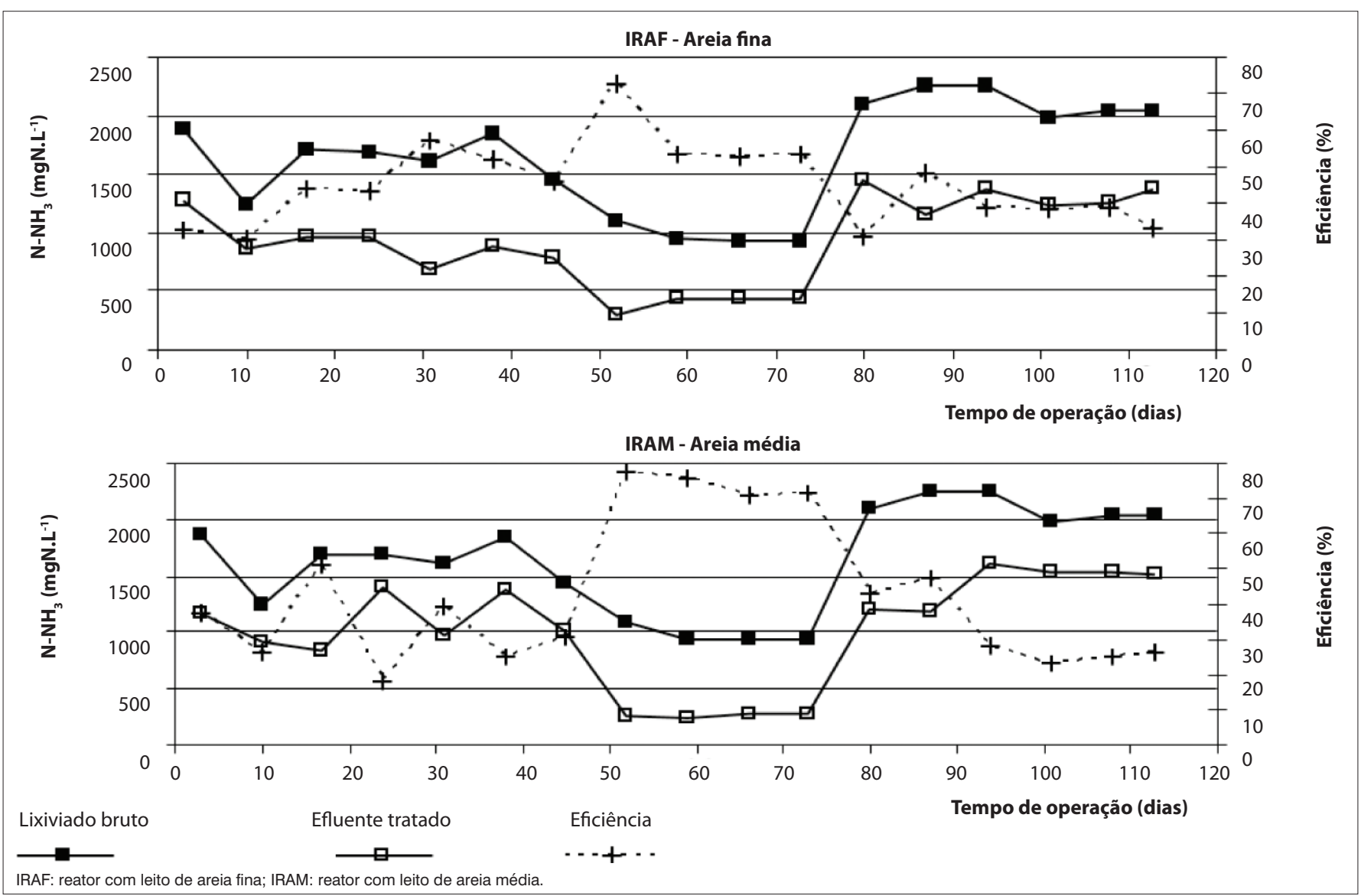

Figura 3 - Variação temporal das concentrações de $\mathrm{N}-\mathrm{NH}_{3}$ na Etapa 2 - Fase 1.
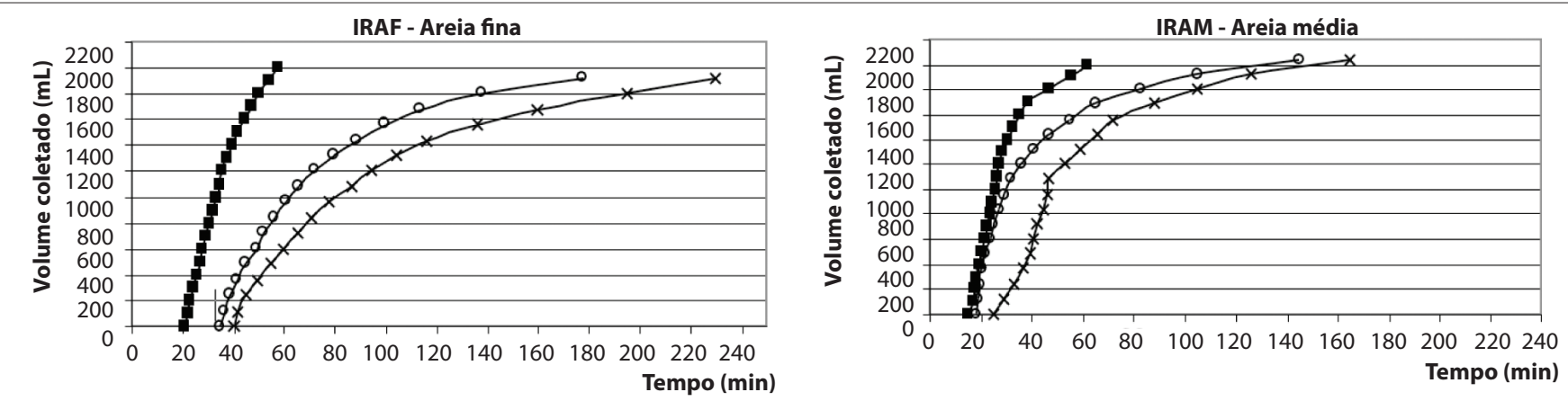

$\rightarrow$ - Início da Etapa $2 \quad \nsucc$ após raspagem de $3 \mathrm{~cm}$

—_após raspagem de $6 \mathrm{~cm}$

IRAF: reator com leito de areia fina; IRAM: reator com leito de areia média.

Figura 4 - Histogramas de vazão dos reatores com leito de Areia Fina e Areia Média no início da operação e após raspagens das camadas colmatadas.

Tabela 4 - Resultados do desempenho dos reatores com leito de Areia Fina e Areia Média Recuperadas na Etapa 2 - Fase 2.

\begin{tabular}{|c|c|c|c|c|c|c|c|c|c|c|c|}
\hline \multirow{2}{*}{ Parâmetros } & \multicolumn{3}{|c|}{ Lixiviado bruto } & \multicolumn{4}{|c|}{ Lixiviado tratado IRAFR } & \multicolumn{4}{|c|}{ Lixiviado tratado IRAMR } \\
\hline & $\mathrm{n}$ & média & DP & $\mathrm{n}$ & média & DP & E (\%) & $\mathrm{n}$ & média & DP & $E(\%)$ \\
\hline $\mathrm{DQO}\left(\mathrm{mgO}_{2} \mathrm{~L}^{-1}\right)$ & 12 & 5.602 & 2.189 & 12 & 3041 & 1.096 & 44,4 & 12 & 2.936 & 1.094 & 45,1 \\
\hline SST $\left(m g \cdot L^{-1}\right)$ & 13 & 177 & 48 & 13 & 77 & 29 & 56,5 & 13 & 72 & 27 & 59,3 \\
\hline N-NTK (mgN.L-1) & 8 & 2.487 & 408 & 8 & 1.149 & 204 & 53,8 & 8 & 1.400 & 257 & 43,7 \\
\hline $\mathrm{N}-\mathrm{NH}_{3}\left(\mathrm{mgN} \cdot \mathrm{L}^{-1}\right)$ & 8 & 1.677 & 386 & 8 & 866 & 200 & 48,4 & 8 & 1.030 & 327 & 38,6 \\
\hline $\mathrm{N}-\mathrm{NO}_{3}^{-}\left(\mathrm{mgN} \cdot \mathrm{L}^{-1}\right)$ & 8 & $<0,001$ & $\mathrm{Na}$ & 8 & 19 & 24 & $\mathrm{Na}$ & 8 & 5 & 14 & $\mathrm{Na}$ \\
\hline $\mathrm{N}-\mathrm{NO}_{2}^{-}\left(\mathrm{mgN} \cdot \mathrm{L}^{-1}\right)$ & 8 & $<0,001$ & $\mathrm{Na}$ & 8 & 0,3 & 0,4 & $\mathrm{Na}$ & 8 & 0,004 & 0,003 & $\mathrm{Na}$ \\
\hline$P_{\text {total }}\left(m g \cdot L^{-1}\right)$ & 8 & 17,9 & 1,9 & 8 & 10,8 & 3,1 & 39,6 & 8 & 13,1 & 2,2 & 26,8 \\
\hline $\mathrm{pH}$ & 8 & 8,3 & 0,3 & 8 & 8,2 & 0,2 & $\mathrm{Na}$ & 8 & 8,3 & 0,2 & $\mathrm{Na}$ \\
\hline Alc. $\left(\mathrm{mgCaCO}_{3} \cdot \mathrm{L}^{-1}\right)$ & 7 & 8.379 & 1.635 & 7 & 5.955 & 1.861 & 28,9 & 7 & 6.489 & 1.505 & 22,6 \\
\hline
\end{tabular}

E: Eficiência de tratamento; Na: não se aplica. DQO: demanda química de oxigênio; SST: sólidos suspensos totais; Ptotal: Fósforo Total; IRAFR: reator com leito de areia fina recuperada; IRAMR: reator com leito de areia média recuperada; Alc.: alcalinidade; DP: desvio-padrão. 
desnitrificação ocorrida em uma camada anaeróbia formada na parte inferior do reator devido à colmatação dos leitos.

Em relação à DQO, houve um aumento de eficiência nos dois reatores, IRAFR $(\mathrm{p}>0,001)$ e IRAMR $(\mathrm{p}=0,011)$ quando comparados a IRAF e IRAM, o que pode ter ocorrido pela renovação da camada colmatada. Quanto aos outros parâmetros, a eficiência do IRAFR teve um aumento não significativo - SST $(p=0,578)$, Ptotal $(p=0,549)$ e $\mathrm{N}-\mathrm{NH}_{3}(\mathrm{p}=0,454)$, e o IRAMR teve um decréscimo não significativo SST $(p=0,088)$, Ptotal $(p=0,051)$ e $\mathrm{N}_{-} \mathrm{NH}_{3}(\mathrm{p}=0,611)$.

\section{Fase 3 - Desempenho dos reatores preenchidos com tijolo cerâmico triturado}

$\mathrm{Na}$ Fase 3, aplicou-se lixiviado a uma taxa de 6,4 cm.dia ${ }^{-1}$, com o mesmo ciclo operacional durante 63 dias. Na Tabela 5 são apresentados os resultados do monitoramento. Nesse período, a temperatura média foi de $24,7^{\circ} \mathrm{C}$, e a taxa média de precipitação foi de $7,31 \mathrm{~mm}$.

$\mathrm{Na}$ Tabela 5 pode-se observar uma eficiência de redução das concentrações de todos os contaminantes superior a dos dois reatores com leito de areia na Etapa 2. Esse fato pode ser atribuído à adsorção, pois materiais argilosos têm maior capacidade de troca cationica do que solos arenosos. O reator IRTC promoveu uma clarificação no lixiviado tratado quando comparado com os reatores com leito de areia. A variação da DQO ao longo do tempo, tanto do lixiviado bruto como do lixiviado tratado do reator IRTC, é mostrada na Figura 7.

Os dados do reator IRTC mostram que apesar da elevada precipitação durante o período, que fez com que as concentrações do lixiviado bruto decaíssem, as concentrações de DQO do lixiviado tratado mantiveram uma regularidade, o que não foi observado nos dois reatores com leito de areia. Isso mostrou que o reator com leito de tijolo cerâmico triturado foi mais estável a mudanças climáticas e de cargas orgânicas. O comportamento dos reatores IRTC ao longo desta Etapa 3 em relação à redução de $\mathrm{N}_{-} \mathrm{NH}_{3}$ são apresentados na Figura 8.

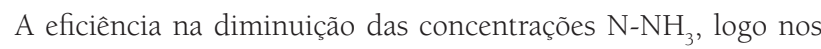
primeiros dias de operação no reator IRTC, foi de 97,8\%. No entanto, essa eficiência regrediu gradativamente durante todo o período, atingindo uma eficiência de 11,82\% no último dia. Essa eficiência elevada logo no início pode ter sido propiciada pela adsorção. As concentrações de nitrito e nitrato no efluente foram significativamente menores que as registradas nos reatores com areia, atingindo um valor máximo de $6,1 \mathrm{mgNO}_{3}^{-} \cdot \mathrm{L}^{-1}$, no $13^{\circ}$ dia

Em todos os reatores, a nitrificação do $\mathrm{N}_{-} \mathrm{NH}_{3}$ não atingiu estabilidade em decorrência do aumento do tempo de retenção e consequente redução da parcela de vazios dos leitos pela colmatação. Essa pouca estabilidade no desempenho dos reatores pode ter sido

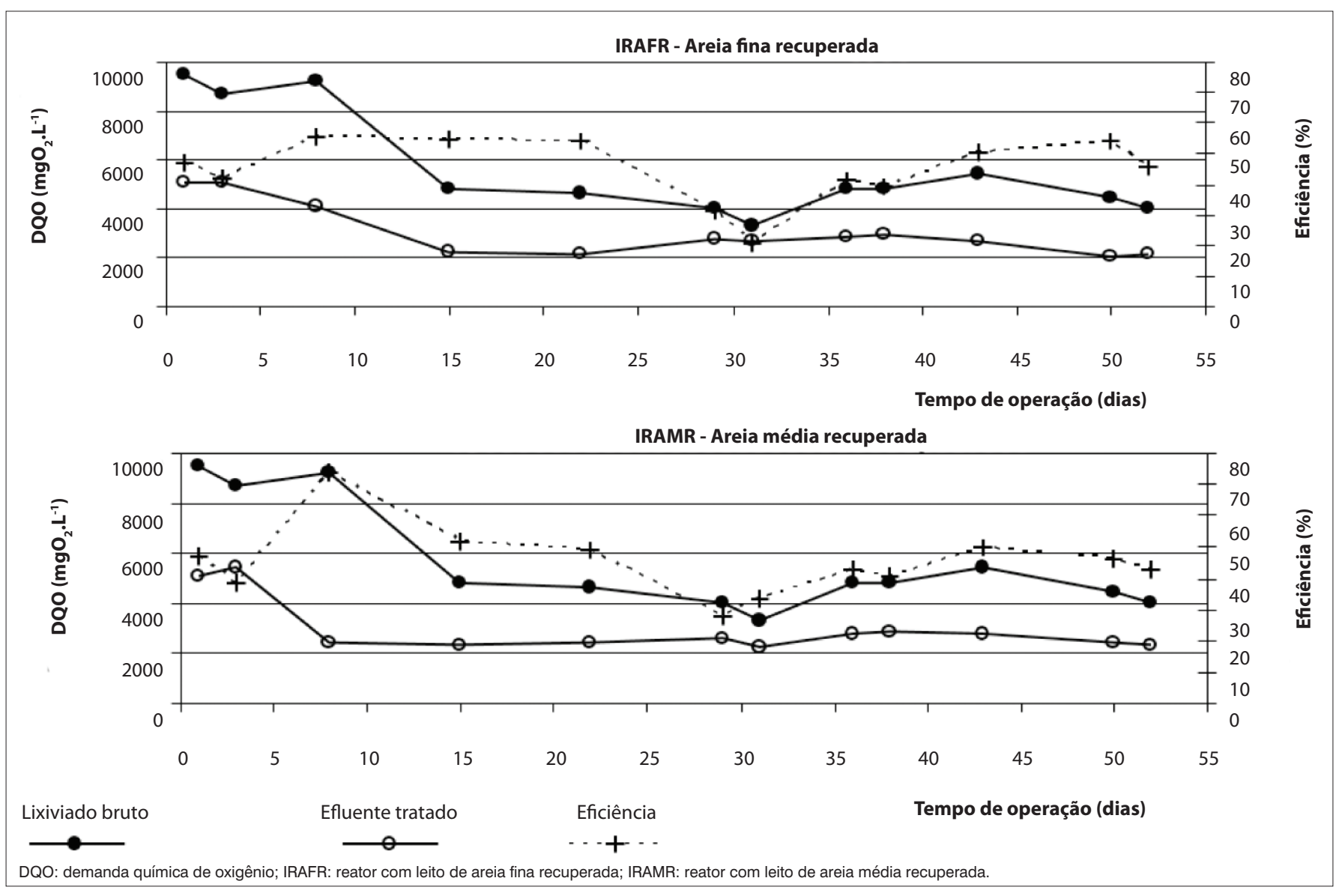

Figura 5 - Variação temporal das concentrações de demanda química de oxigênio na Etapa 2 - Fase 2. 


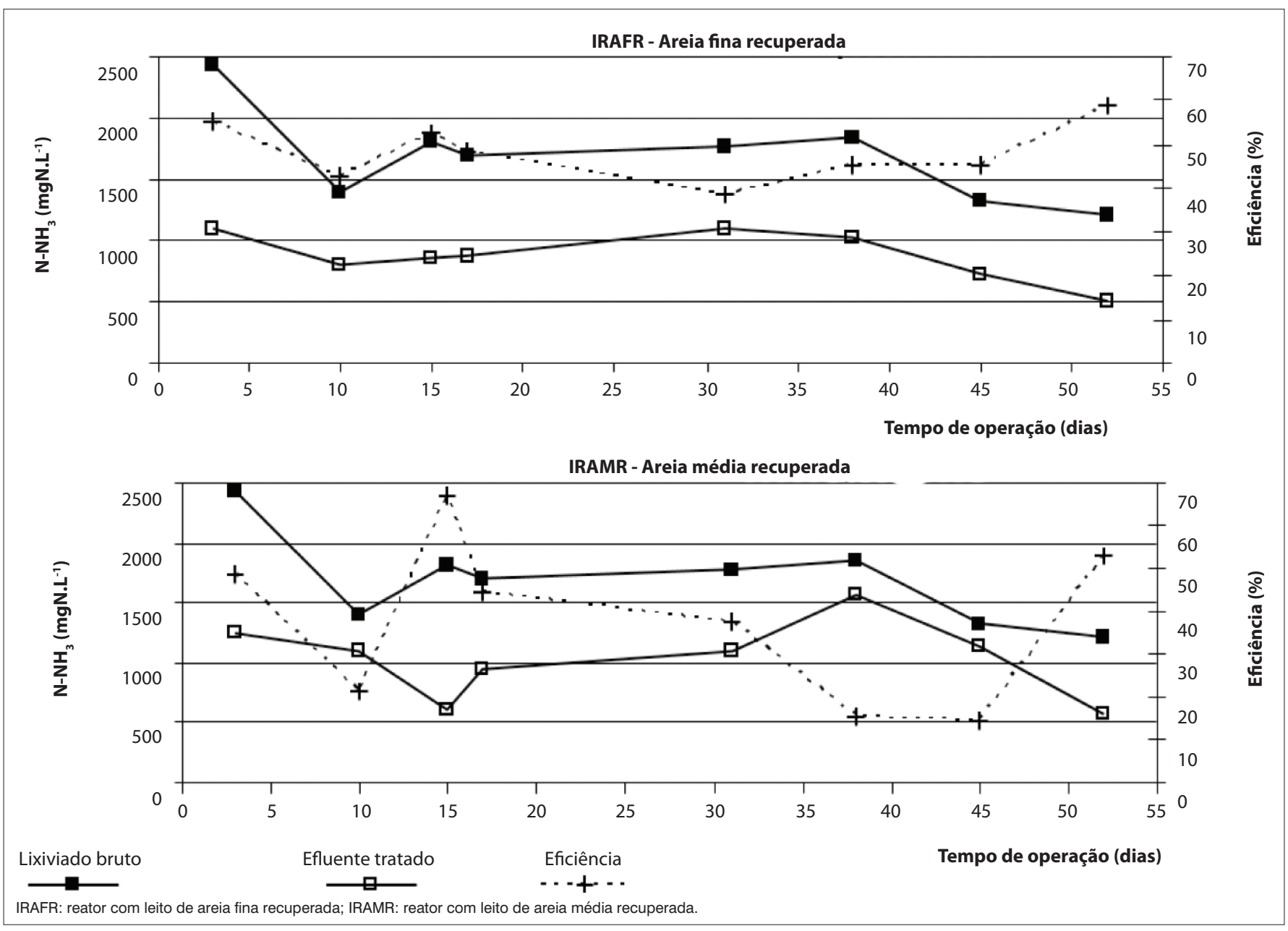

Figura 6 - Variação temporal das concentrações de $\mathrm{N}^{-\mathrm{NH}_{3}}$ na Etapa 2 - Fase 2.

Tabela 5 - Resultados do desempenho do reator preenchido com tijolo cerâmico triturado - Etapa 3.

\begin{tabular}{|c|c|c|c|c|c|c|c|}
\hline \multirow{2}{*}{ Parâmetros } & \multicolumn{3}{|c|}{ Lixiviado bruto } & \multicolumn{4}{|c|}{ Lixiviado tratado IRTC } \\
\hline & $\mathrm{n}$ & média & DP & $\mathrm{n}$ & média & DP & $E(\%)$ \\
\hline $\mathrm{DQO}\left(\mathrm{mgO}_{2} \cdot \mathrm{L}^{-1}\right)$ & 15 & 5.280 & 2.052 & 15 & 1.539 & 406 & 71 \\
\hline SST (mg. $\left.\mathrm{L}^{-1}\right)$ & 16 & 177 & 41 & 16 & 38 & 27 & 79 \\
\hline N-NTK (mgN.L-1) & 13 & 2.459 & 419 & 13 & 1.053 & 390 & 57 \\
\hline $\mathrm{N}-\mathrm{NH}_{3}\left(\mathrm{mgN} \cdot \mathrm{L}^{-1}\right)$ & 13 & 1.714 & 353 & 13 & 839 & 388 & 51 \\
\hline $\mathrm{N}-\mathrm{NO}_{3}^{-}\left(\mathrm{mgN} \cdot \mathrm{L}^{-1}\right)$ & 13 & $<0,001$ & $\mathrm{Na}$ & 13 & 3,1 & 1,8 & $\mathrm{Na}$ \\
\hline $\mathrm{N}-\mathrm{NO}_{2}^{-}\left(\mathrm{mgN} \cdot \mathrm{L}^{-1}\right)$ & 13 & $<0,001$ & $\mathrm{Na}$ & 13 & 0,5 & 0,7 & $\mathrm{Na}$ \\
\hline$P_{\text {total }}\left(m g \cdot L^{-1}\right)$ & 10 & 17,7 & 1,9 & 10 & 0,84 & 0,5 & 95 \\
\hline $\mathrm{pH}$ & 9 & 8,4 & 0,3 & 9 & 7,6 & 1,0 & - \\
\hline Alc. $\left(\mathrm{mgCaCO}_{3} \cdot \mathrm{L}^{-1}\right)$ & 9 & 8.266 & 1.434 & 9 & 3.414 & 1.925 & 59 \\
\hline
\end{tabular}

E: eficiência de tratamento; Na: não se aplica; DQO: demanda química de oxigênio; SST: sólidos suspensos totais; Ptotal: Fósforo Total; IRTC: reator preenchido com tijolo cerâmico triturado; Alc.: alcalinidade; DP: desvio-padrão.

agravada pelas altas concentrações e pela grande variação de $\mathrm{N}-\mathrm{NH}_{3}$ e de DQO do lixiviado bruto.

Fase 4 - Análise dos leitos a serem descartados como resíduos sólidos

Nos reatores com leito de areia, o volume de resíduos gerado com a camada colmatada foi o equivalente a uma taxa de 90L.m ${ }^{-2}$.ano. Nos reatores com leito de tijolo cerâmico triturado, o resíduo gerado foi o equivalente a uma taxa de $72 \mathrm{~L} . \mathrm{m}^{-2}$.ano, ou seja, $20 \%$ a menos que os reatores de areia.

Foram realizadas análises de metais pesados $\mathrm{Cd}$ e $\mathrm{Pb}$ nos extratos lixiviados e $\mathrm{Cd}, \mathrm{Pb}, \mathrm{Cu}$, Fe, Mn e $\mathrm{Zn}$ nos extratos solubilizados, obtidos conforme a ABNT (2004b, 2004c), de amostras coletadas nas camadas colmatadas dos reatores IRAF, IRAM e IRTC. As amostras 


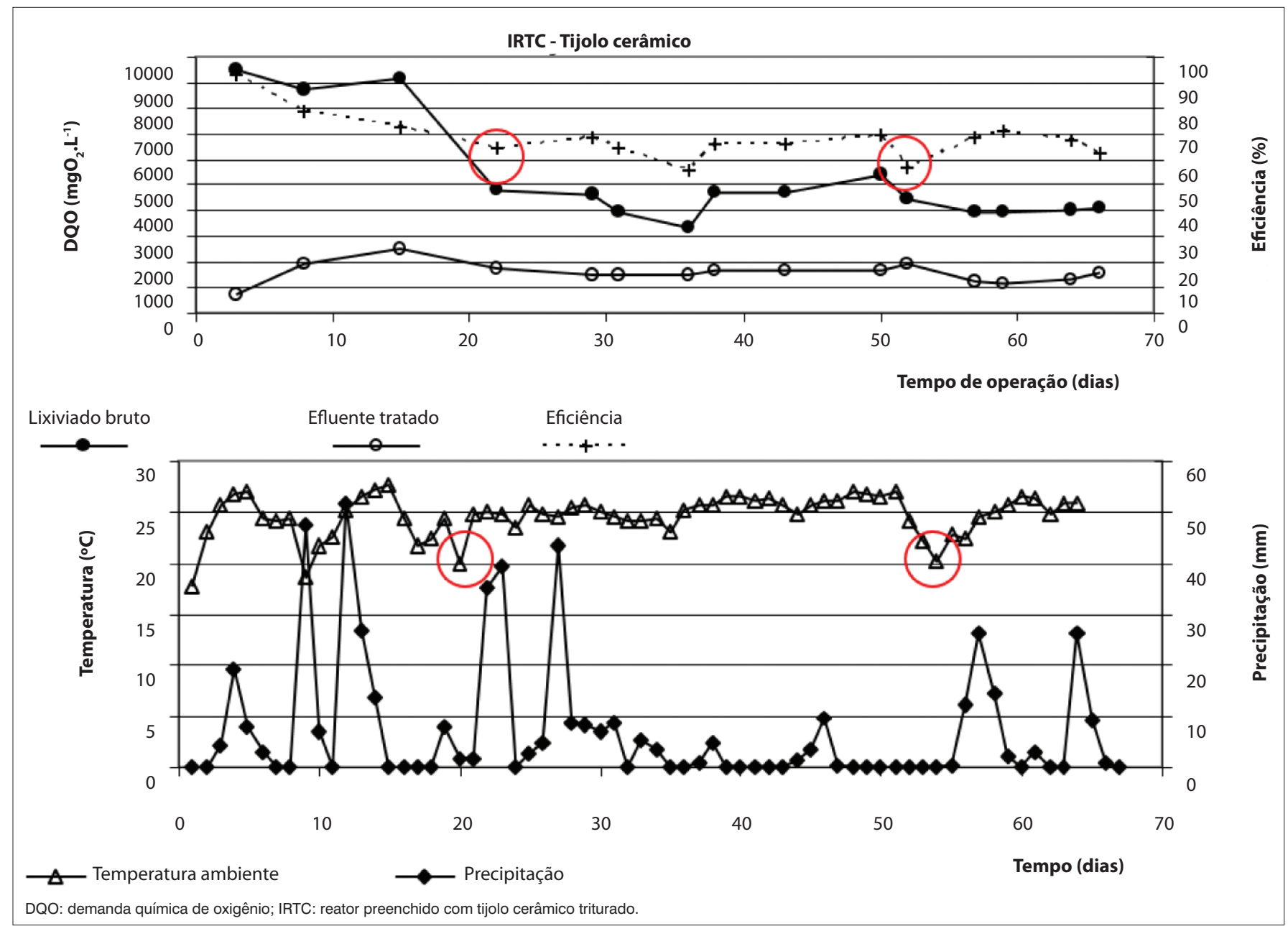

Figura 7 - Variação temporal das concentrações de demanda química de oxigênio na Etapa 3 e variação de temperatura e precipitação.

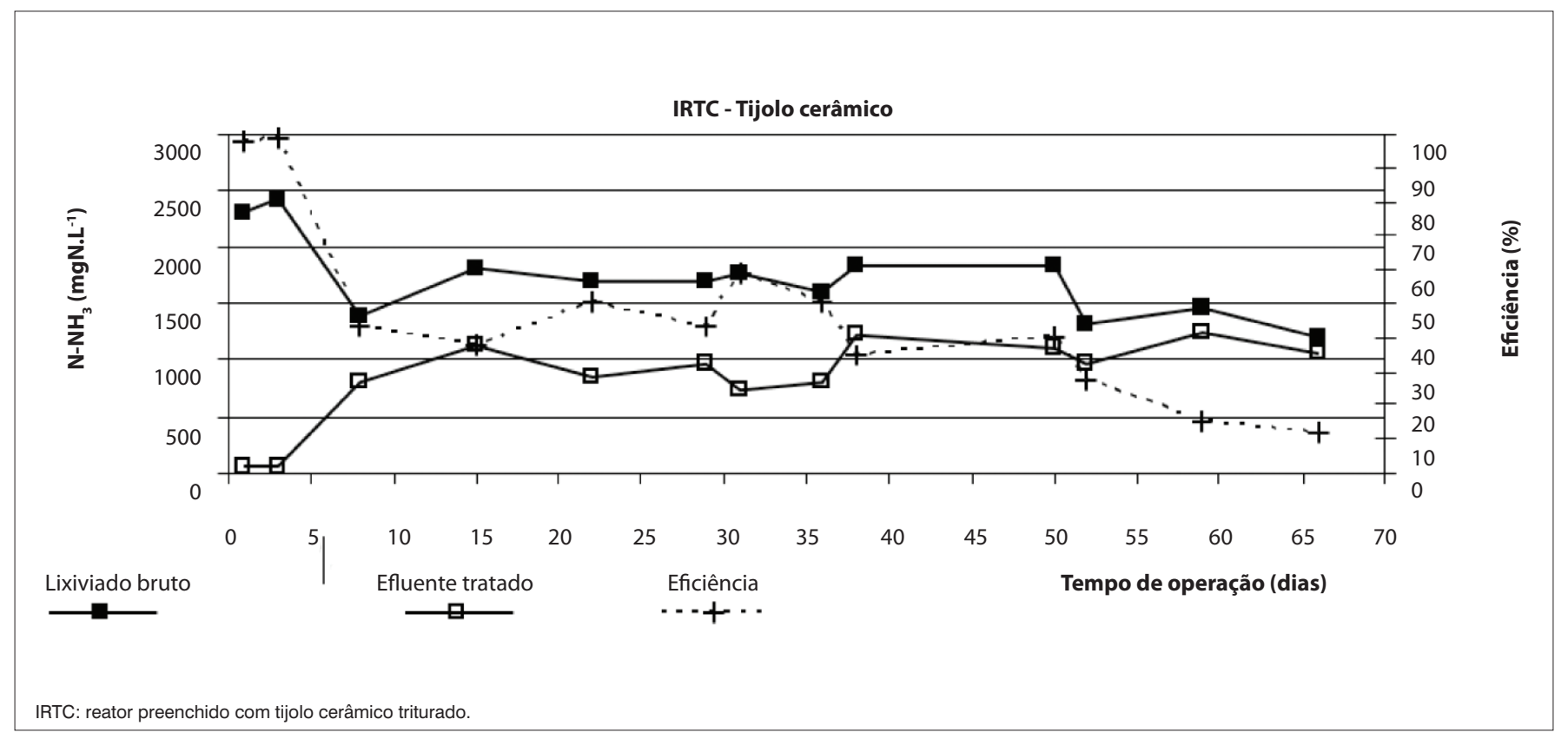

Figura 8 - Variação temporal das concentrações de $\mathrm{N}-\mathrm{NH}_{3}$ na Etapa 3. 
dos materiais que tiveram contato com lixiviado apresentam enriquecimento por todos os íons analisados em relação às amostras de referência. Para os três materiais analisados, as concentrações de Fe no extrato solubilizado das amostras foi o metal que apresentou valores acima do limite estabelecido na norma. $\mathrm{Na}$ análise de $\mathrm{pH}$, os materiais das camadas colmatadas não apresentaram características de corrosividade uma vez que mantiveram pH entre 2 e 12,5, faixa estabelecida pela ABNT (2004a).

\section{Conclusões}

O processo de IR apresentou-se satisfatório para um tratamento primário de lixiviado de aterro sanitário, quando utilizados materiais convencionais no leito filtrante, como areia média e fina. A eficiência na remoção de DQO, SST, Ptotal e $\mathrm{N}_{-} \mathrm{NH}_{3}$ para reatores com areia média e fina mostrou-se estatisticamente igual, no entanto a colmatação foi mais intensa em profundidade no reator com leito de areia fina.

Em termos de carga orgânica, o sistema estudado com leitos de areia demonstrou suportar grandes variações DQO e SST, visto que não houve perda de eficiência embora quando do aumento das concentrações no lixiviado bruto tenha havido um aumento das concentrações no lixiviado tratado.

Nos três reatores, ocorreu uma evolução das diferentes formas de nitrogênio. $O$ nitrogênio amoniacal é a forma mais representativa no lixiviado. Foi observada a ocorrência do processo de nitrificação. Uma intensa atividade foi observada quando as concentrações de $\mathrm{N}-\mathrm{NH}_{3}$ apresentaram valores mais baixos no lixiviado tratado, atingindo uma eficiência máxima de 73\% no IRAF e 77\% no IRAM na nitrificação do nitrogênio amoniacal.

Houve uma nitrificação de 43 e 38\% da amônia do lixiviado bruto após tratamento no IRAF e IRAM, no entanto os valores de $\mathrm{N}_{-\mathrm{NH}_{3}}$ no lixiviado tratado ainda foram de $931 \mathrm{mgN} . \mathrm{L}^{-1}$ e $1014 \mathrm{mgN} . \mathrm{L}^{-1}$ respectivamente, o que não atende aos padrões de lançamento de efluentes conforme estabelecido pela Resolução CONAMA no 430/2011.
O reator IRTC apresentou uma eficiência de nitrificação de $51 \%$ e remoção quase que total do nitrogênio nitrificado, apresentando no lixiviado tratado concentrações de nitrato inferiores a $8 \mathrm{mg} \cdot \mathrm{L}^{-1}$. A eficiência na redução das concentrações de DQO, SST e Ptotal foram superiores aos observados nos reatores com leito areia. As concentrações de DQO e SST no lixiviado tratado mantiveram-se estáveis, mesmo com grandes variações nas concentrações do lixiviado bruto aplicado. O material cerâmico, por ter como matéria prima a argila, que tem alta capacidade de adsorção e troca catiônica, apresentou vantagens adsortivas em relação aos leitos de areia, além de ser um aproveitamento de resíduos de material de construção civil.

Quando comparado a resultados obtidos em outros estudos com tratamento biológico semelhante, observam-se eficiências superiores neste estudo. Bidone, Povinelli e Cotrim (1997) obtiveram 16,5\% de eficiência na remoção de DQO, comparado a 71\% obtido neste estudo para processos de infiltração rápida utilizando leitos com cacos de tijolos. Na remoção de Ptotal, a eficiência foi de 53\% comparado a $95 \%$ deste estudo. Quanto à remoção de $\mathrm{N}-\mathrm{NH}_{3}$, a eficiência foi superior, com $66 \%$ comparado a $47 \%$ deste estudo.

A técnica de Infiltração Rápida como processo primário de tratamento biológico se mostrou eficiente e de fácil operação, com potencial de ser aplicada para tratar lixiviados de aterros de municípios de pequeno porte, geralmente com escassez de recursos financeiros, poucas áreas apropriadas e disponíveis, além de pouca mão de obra técnica especializada.

Quando a técnica IR for aplicada em projetos em escala real, recomenda-se a realização de estudos em escala próxima a real, em tanques de alvenaria de tijolos ou concreto, levando em consideração as características climáticas e do lixiviado. No caso de reator preenchido com material cerâmico triturado, os estudos devem ser realizados em um maior período de tempo, variando taxas, ciclos e granulometria. Certamente, para atender padrões legais de lançamento em corpos receptores, se fará necessário a conjugação com outra técnica.

\section{Referências}

ABNT - Associação Brasileira de Normas Técnicas. (1988) NBR 7181: Solo - Análise granulométrica. Rio de Janeiro, 1988,

ABNT - Associação Brasileira de Normas Técnicas. (2004a) NBR 10004: Resíduos Sólidos: Classificação. Rio de Janeiro, 2004a.

ABNT - Associação Brasileira de Normas Técnicas. (2004b) NBR 10005: Procedimento para obtenção de extrato de lixiviado de resíduos sólidos. Rio de Janeiro, 2004b.

ABNT - Associação Brasileira de Normas Técnicas. (2004c) NBR 10006: Procedimento para obtenção de extrato de solubilizado de resíduos sólidos. Rio de Janeiro, 2004c.
APHA; AWWA; WEF. (2005) Standard methods for the examination of water and wastewater. 19th ed. New York: American Public Health Association. $1268 \mathrm{p}$.

BIDONE, F.R.A.; POVINELLI, J.; COTRIM, S.L.S. (1997) Tratamento de lixiviado de aterro sanitário através de filtros percoladores. In: $19^{\circ}$ Congresso Brasileiro de Engenharia Sanitária e Ambiental. Anais... Foz do Iguaçu: ABES. CD-ROM, III - 010.

BRASIL. Resolução CONAMA no 430/2011, de 13 de maio de 2011 Dispõe sobre condições e padrões de lançamento de efluentes, complementa e altera a Resolução no 357, de 17 de março de 2005, do Conselho Nacional do Meio Ambiente - CONAMA. Diário Oficial da União, 16 de maio de 2011, p. 89. 
BRAGA, F.S. (1998) Disposição de esgotos sanitários por infiltração rápida, sob condições de campo e de laboratório, em solo arenoso de região litorânea. 237 p. Tese (Doutorado em Hidráulica e Saneamento) - Escola de Engenharia de São Carlos, Universidade de São Paulo, São Carlos, 1998.

COUTO, M.C.L. (2004) Tratamento de chorume de aterro sanitário por infiltração rápida em reatores em escala piloto. 133 p. Dissertação (Mestrado em Engenharia Ambiental) - Universidade Federal do Espírito Santo, Vitória.

ELDYASTI, A.; ANDALIB, M.; HAFEZ, H.; ZHU, J. (2011) Comparative modeling of biological nutrient removal from landfill leachate using a circulating fluidized bed bioreactor. Journal of Hazardous Materials, v. 187, n. 1, p.140-149

GOMES, L.P. (Coord.) (2009) Estudos de caracterização e tratabilidade de lixiviados de aterros sanitários para as condições brasileiras. Rio de Janeiro: Ed. ABES. $360 \mathrm{p}$.

JOKELA, J.P.Y.; KETTUNEN, R.H.; SORMUNEN, K.M.; RINTALA, J.A. (2002) Biological nitrogen removal from municipal landfill leachate: low- cost nitrification in biofilters and laboratory scale in-situ denitrification. Water Research, v. 36, p. 4079-4087.

LEKANG, O.I. \& KLEPPE, H. (2000) Efficiency of nitrification in trickling filters using different filter media. Aquacultural engineering, v. 21, p.181-199.

RENOU, S.; GIVAUDAN, J.G.; POULAIN, S.; MOULIN, P. (2008) Landfill leachate treatment: Review and opportunity. Journal of Hazardous Materials, v. 150, n. 3, p. 468-493.

SANFORD, W.E. STEENHUIS, T.S.; SURFACEM J.M.; PEVERLY, J.H. (1995) Flow characteristics of rock-reed filters for treatment of landfill leachate. Ecological Engineering, v. 5, p. 37-50.

WELANDER, U.; HENRYSSON, T.; WELANDER, T. (1998) Biological nitrogen removal from municipal landfill leachate in a pilot scale suspended carrier biofilm process. Water Research, v. 32, n. 5, p. 1564-1570.

YIDONG, G.; XIN, C.; SHUAI, Z.; ANCHENG, L. (2012) Performance of multi-soil-layering system (MSL) treating leachate from rural unsanitary landfills. Science of The Total Environment, v. 420, p. 183-190. 
